\title{
Investigating modes of being in the world: an introduction to Phenomenologically grounded qualitative research
}

\author{
Allan Køster ${ }^{1,2} \cdot$ Anthony Vincent Fernandez ${ }^{3,4}$
}

Accepted: 10 December 2020 / Published online: 16 February 2021

(C) The Author(s) 2021

\begin{abstract}
In this article, we develop a new approach to integrating philosophical phenomenology with qualitative research. The approach uses phenomenology's concepts, namely existentials, rather than methods such as the epoché or reductions. We here introduce the approach to both philosophers and qualitative researchers, as we believe that these studies are best conducted through interdisciplinary collaboration. In section 1, we review the debate over phenomenology's role in qualitative research and argue that qualitative theorists have not taken full advantage of what philosophical phenomenology has to offer, thus motivating the need for new approaches. In section 2, we introduce our alternative approach, which we call Phenomenologically Grounded Qualitative Research (PGQR). Drawing parallels with phenomenology's applications in the cognitive sciences, we explain how phenomenological grounding can be used to conceptually front-load a qualitative study, establishing an explicit focus on one or more structures of human existence, or of our being in the world. In section 3 , we illustrate this approach with an example of a qualitative study carried out by one of the authors: a study of the existential impact of early parental bereavement. In section 4, we clarify the kind of knowledge that phenomenologically grounded studies generate and how it may be integrated with existing approaches.
\end{abstract}

Keywords Phenomenology · Applied phenomenology · Qualitative research · Qualitative methods · Heidegger

Allan Køster

allankoester@gmail.com

Anthony Vincent Fernandez

Fernandez.Anthony.V@gmail.com

Extended author information available on the last page of the article 


\section{Introduction}

Phenomenology is a philosophical investigation of experience, subjectivity, and the lifeworld. But the human and social sciences, including psychology, education, anthropology, and nursing, have adapted it as a paradigm for qualitative research. ${ }^{1}$ In many adaptations, they take phenomenology's philosophical methods - such as the epoché and the hermeneutic circle - and transform them into empirical methods that facilitate interviewing and data analysis. In other adaptations, an approach is called phenomenological simply because it investigates experience from the first-person perspective. ${ }^{2}$ However, while these qualitative researchers draw from the philosophical texts, many have developed their qualitative methodologies without collaborating with philosophically trained phenomenologists.

In this article, we propose an approach to integrating philosophical phenomenology with qualitative research that uses phenomenology's concepts, rather than its methods, to ground the domain or focus of a qualitative study. We here introduce the approach to both philosophers and qualitative researchers, as we believe that these studies are best conducted through interdisciplinary collaboration. In section 1, we review the debate over phenomenology's role in qualitative research and argue that qualitative theorists have not taken full advantage of what philosophical phenomenology has to offer, thus motivating the need for new approaches. In section 2, we introduce our alternative approach, which we call Phenomenologically Grounded Qualitative Research (PGQR). Drawing parallels with phenomenology's applications in the cognitive sciences, we explain how phenomenological grounding can be used to conceptually front-load a qualitative study, establishing an explicit focus on one or more structures of human existence, or of our being in the world. In section 3, we illustrate this approach with an example of a qualitative study carried out by one of the authors: a study of the existential impact of early parental bereavement. In section 4, we clarify the kind of knowledge that phenomenologically grounded studies generate and how it may be integrated with existing approaches.

\section{Phenomenology and qualitative research: The state of the debate}

Most phenomenological qualitative theorists claim roots in the philosophical tradition of phenomenology. But the degree to which their approaches are genuinely phenomenological has become a matter of debate. Both Amedeo Giorgi (2010) and Max van Manen (2017) have questioned the philosophical foundations of Jonathan Smith's Interpretative Phenomenological Analysis (IPA), one of the most popular phenomenological approaches to qualitative research today. Smith $(2010,2018)$ defended the philosophical foundations of his approach, arguing that it draws extensively from the

\footnotetext{
${ }^{1}$ Some of the better-known approaches have been developed by Peter Ashworth (2003); Paul Colaizzi (1978); Karin Dahlberg et al. (2008); Amedeo Giorgi (2009); Darren Langdridge (2007); Max van Manen (2016); Claire Petitmengin (2006); and Jonathan Smith et al. (2009).

${ }^{2}$ Shaun Gallagher argues that some of these approaches even fail to reach the lived experience of the interviewee, instead arriving at opinions or explanations for how the interviewee felt about an experience (2012, 306).
} 
classic phenomenological and hermeneutic texts, including the work of Edmund Husserl, Martin Heidegger, and Hans-Georg Gadamer. But both Giorgi (2011) and van Manen (2018) remain unconvinced. Giorgi acknowledged that Smith's method has some hermeneutic inspiration; but he argued that Smith fundamentally misinterprets key aspects of the phenomenological method, specifically with respect to notions of bracketing and the reduction. Van Manen took a similar line of argument, suggesting that Smith fails to distinguish phenomenological from psychological methods. Following van Manen's most recent critique, Dan Zahavi (2018, 2019; Zahavi and Martiny 2019) questioned the philosophical foundations of both Giorgi's and van Manen's approaches. He argued that they misinterpret or (at least in the case of Giorgi) misapply various aspects of the phenomenological method - especially the epoché or reduction. Van Manen (2019) defended his own position and James Morley (2019) defended Giorgi's. But the debate continues, with Zahavi (2020) leveling a further critique against van Manen's approach.

These approaches derive much of their legitimacy from their philosophical lineage, which is now in question. And, in the wake of these debates, many qualitative researchers have become skeptical of phenomenological approaches. But this skepticism and concern has proved productive. Already, qualitative theorists have taken the opportunity to clarify their use of phenomenology, including their phenomenological approach to interviews. ${ }^{3} \mathrm{We}$ expect that this trend will continue, with current methodologies clarified in productive ways.

The approach that we introduce here, however, diverges in significant respects from the dominant approaches to phenomenological qualitative research (including those of Giorgi, van Manen, and Smith). Our approach does not adapt philosophical phenomenology's methods, although it may be compatible with approaches that use such methods. Rather, our approach draws on philosophical phenomenology's concepts - specifically, what phenomenologists call "invariant" or "existential" structures, and what Heidegger refers to, simply, as "existentials." As we explain in the following section, these structural features of human existence, or being in the world, can be used to ground the domain of a qualitative study. They provide a framework that allows the qualitative researcher to focus on a specific feature of human existence and investigate its particular modes. In so doing, our approach takes advantage of many of phenomenology's philosophical concepts in ways that other approaches to qualitative research do not. 4

\footnotetext{
${ }^{3}$ One example is found in the work of Magnus Englander, who had previously written on phenomenological approaches to interviewing (Englander 2012) but, following Zahavi's critique, returned to the topic and clarified his position (Englander 2020).

${ }^{4}$ Readers who are familiar with phenomenological approaches to qualitative research may recognize an apparent similarity with the work of van Manen (1990, 2016), Ashworth (2003, 2016), and Les Todres et al., (2007; see also Dahlberg et al., 2009; Todres et al., 2009). All of these authors appeal to existentials, although they may refer to them under different names (Ashworth calls them "fractions of the life-world" and Todres, Galvin, and Dahlberg call them "constituents of the lifeworld"). One distinctive feature of our approach is the use of a single existential or a selection of existentials to determine the scope of the study in advance. This allows for a highly focused study of a specific structural feature of human existence, such as temporality, spatiality, selfhood, or affectivity. In this respect, our approach shares much in common with the method of conceptual front-loading used in phenomenology's successful application in the cognitive sciences (Gallagher 2003).
} 


\section{Phenomenologically grounded qualitative research}

What is phenomenological grounding? The general idea is fairly simple: Philosophical phenomenology provides a rich account of the essential structures of being in the world, which we refer to as "existentials." These include intentionality, selfhood, empathy, embodiment, temporality, spatiality, and affectivity, among others. ${ }^{5}$ The existentials provide a conceptual framework that qualitative researchers can use to organize and focus the domain of their study. For example, rather than ask how chronic illness shapes one's experience in general, we can ask how chronic illness shapes one's temporal experience, embodied experience, sense of self, and so on. And each of these might be investigated in more detail. With respect to embodied experience, we might ask how illness disrupts one's habituated styles of bodily movement, how it alters one's bodily engagement with one's environment, or how it modifies one's bodily experience in social interactions. Phenomenologically grounded studies will, therefore, have clearly delimited research questions and aims for the interview - at least in comparison to most phenomenological qualitative approaches.

In this section, we introduce the basics of phenomenological grounding as a qualitative research methodology. First, we clarify the distinction between existentials and modes. This is key to distinguishing between ontological and ontic studies in phenomenology. Second, we explain how to design a phenomenologically grounded study, drawing analogies with how phenomenology has been successfully integrated with cognitive science research. In this introductory article, we do not discuss methods of interviewing or data analysis in detail. ${ }^{6}$ We will return to these stages of PGQR in future work.

\subsection{Existentials and modes}

We use "existentials" as a synonym for what phenomenologists call "invariant," "existential," or "ontological" structures. The existentials are the constitutive elements of human existence, or being in the world. Moreover, we follow Heidegger in acknowledging that being in the world is a unified phenomenon: "Being-in-the-world is a structure which is primordially and constantly whole" (Heidegger [1927] 1962, 225). This means that these constitutive elements aren't independent of each other. But even Heidegger had to investigate being in the world through its "constitutive items," that is, its existentials. Analyzing the structure of human existence in this way is a necessary starting point, even if our goal is to provide a more unified account. In much the same way, when we perform qualitative studies of particular ways of being in the world, it's best to start from specific existentials, even if our ultimate goal is to provide an account of this way of being in its totality.

But qualitative researchers aren't typically interested in the existentials themselves. They don't engage in the philosophical articulation of the invariant structural features of human existence, such as temporality, selfhood, and so on. If the analysis of existentials is, for the most part, a philosophical project, then why should qualitative

\footnotetext{
${ }_{5}^{5}$ To our knowledge, no one has attempted to provide an exhaustive list of existentials and no one has provided necessary and sufficient criteria for determining what counts as an existential. However, there's general agreement among phenomenologists on what these key structures are, although they may have different ways of describing and distinguishing them.

${ }^{6}$ For recommendations on philosophically informed approaches to phenomenological interviewing, see Høffding and Martiny (2016) and Gallagher and Francesconi (2012).
} 
researchers care about existentials? On our approach, a phenomenologically grounded qualitative study investigates what we call a "mode" of an existential. This is a way of being that is, to some degree, particular. This might include a way of being that is considered characteristically masculine or feminine, a way of being that is culturally specific, a way of being that arises from living through a particular kind of life event, and so on. It might be an individual's way of being. But, in most cases, the researcher will be interested in the way of being of a particular class of subjects (e.g., people diagnosed with borderline personality disorder (Køster 2017a), people who are refugees in western Europe, or people living with a long-term disability). When we articulate what's distinctive about these ways of being, we're not describing the existentials or the invariant structural features of human existence. We use the existentials as a guide or framework for an empirical study of particular ways of being.

How should we think of the relationship between existentials and modes? We can think of each existential as a category and the modes as the phenomena that belong to this category (Fernandez 2017; Fernandez and Køster 2019). We can illustrate this distinction with an example from Heidegger. We may, for instance, articulate the general structure of affective situatedness [Befindlichkeit]. As Heidegger argues, we always find ourselves attuned to the world through some mood or other; our moods disclose the world (and ourselves) and allow things to matter to us. When he articulates the structure and function of affective situatedness, he doesn't describe any particular mood. He describes the structure of affective situatedness in general - the existential itself.

But Heidegger also describes modes of affective situatedness, that is, particular moods. These include, among others, anxiety, joy, and boredom. When he describes these moods, his phenomenological investigation takes on a fundamentally new kind of object. He's no longer engaged in fundamental ontology - that is, an analysis of the general structure of being in the world. Rather, he's now engaged in a study of particular modes, or ways, of being in the world, which he refers to as "ontic" studies (Heidegger [1927] 1962, 172). In this case, he describes particular modes of affective situatedness. What's important here is the distinction between (a) the (ontological) investigation of moods as such and (b) the (ontic) investigation of particular moods. We can draw the same distinction for all of the existentials. For example, we can describe the general structure of temporality; but we can also describe the particular temporal modes of whiling away the time or of eager anticipation. Alternatively, we can describe the general structure of body image; but we can also describe the body image of a particular person or class of people. These are two fundamentally different kinds of projects. The former is ontological; the latter is ontic (see, e.g., Heidegger [1987] 2001, 207). And, for our purposes, the former provides a framework for the latter. ${ }^{7}$ In section

\footnotetext{
${ }^{7}$ We acknowledge that there are competing interpretations of what Heidegger means by "fundamental ontology" and what the relationship is between ontological and ontic investigations in his work. To provide a clear and viable approach to applied phenomenology, we put some of these interpretive debates aside and simply rely on an interpretation that's useful for qualitative researchers. However, we do believe that our distinction between the ontological and the ontic is largely consistent with Heidegger's characterization in the Zollikon Seminars, where he explains to a group of psychiatrists that their studies of mental illnesses are ontic, whereas his own studies of being in the world are ontological (Fernandez 2018; Heidegger [1987] 2001, 207). There's also a sense in which investigations of particular phenomena (e.g., particular moods) provide resources for articulating the general features that hold for this entire class of phenomena (e.g., moods as such). However, for the sake of simplicity, we will not discuss this aspect of phenomenological research here.
} 
3, we provide a detailed example of how this approach has been used in a qualitative study. However, before we get to the illustration, we need to explain how existentials can inform qualitative research.

\subsection{Preparing a phenomenologically grounded study}

It's not enough to say that philosophical phenomenologists study existentials and phenomenological qualitative researchers study the modes of existentials. We need to describe how, exactly, the existentials inform the design of a qualitative study. To clarify this stage of phenomenological grounding, we draw parallels between two approaches to integrating phenomenology with the cognitive sciences. The first is "retrospective" phenomenology. The second is "front-loaded" phenomenology (Gallagher 2003; Gallagher and Zahavi 2012).

Retrospective phenomenology involves the interpretation, or reinterpretation, of already existing empirical data or analyses. Glenn Braddock (2001) defends this use of phenomenology. But the approach itself is not new. One of the best examples is Merleau-Ponty's reinterpretation of the case of Schneider, a World War One veteran whose perception and motility were fundamentally altered following a brain injury. Schneider's case was originally studied by the psychologist, Adhemar Gelb, and the neurologist, Kurt Goldstein. Together, Gelb and Goldstein collected observational accounts of Schneider's behavior and first-person reports from Schneider himself. They then analyzed and interpreted this data, providing an account of how Schneider's lived world had altered. Merleau-Ponty critically reinterpreted Gelb and Goldstein's data and analyses, providing a competing phenomenological account of Schneider's condition. He argued that Schneider lost what he calls "the function of projection." Conscious life is, according to Merleau-Ponty, "underpinned by an 'intentional arc' that projects around us our past, our future, our human milieu, our physical situation, our ideological situation, and our moral situation" ([1945] 2012, 137). He says that Schneider, having lost this function, is bound to his current situation-he can't imagine other possibilities for himself, speculate about the future, and so on. Here, Merleau-Ponty's use of phenomenology is retrospective: He uses a phenomenological understanding of experience to critically assess previous scientific analyses and provide alternative interpretations of how experience has been altered or disturbed. Gallagher acknowledges that this approach can produce competing interpretations of a case. But it's important to keep in mind that these interpretations are not conclusive. As he says, "Merleau-Ponty's account of the case remains simply one of several possible theoretical accounts" (Gallagher 2003, 89). This kind of retrospective interpretation, when employed in the context of experimental cognitive science, generates testable hypotheses. It does not provide definitive conclusions. If one's interpretation of a case is accurate, then it should, in principle, stand up to experimental testing.

When using a retrospective approach in the design of qualitative study, the researcher should consult both the relevant scientific literature (e.g., previous psychological and/or qualitative studies) and first-person descriptions (e.g., memoirs, previous interviews, etc.). As we'll illustrate in section 3, a phenomenologically informed interpretation may identify aspects of a condition, or way of being, that's been neglected in previous studies. Or, alternatively, the phenomenological orientation may provide a more nuanced interpretation of an experience that's already been studied. For example, 
a researcher may review previous studies of bodily objectification in health care settings. By critically reviewing the results of these studies in light of their phenomenological understanding of embodiment, they may be able to conceptually distinguish among different kinds of bodily objectification that haven't been disambiguated in existing studies. This provides the groundwork for developing a new study that will focus on specific modes of bodily objectification and provide more nuanced insight into these kinds of experiences.

After identifying the specific aspect of being in the world that the researcher wants to investigate, they should turn to the front-loading process. Here, again, it's helpful to review how this approach has been successfully used within the cognitive sciences. According to Gallagher, the retrospective approach can produce alternative interpretations that generate new hypotheses for empirical (in his case, experimental) research. Front-loading, in contrast, is used to design the studies that will test the hypothesis. The cognitive scientist can draw upon phenomenological concepts and conceptual distinctions to frame their empirical study. The front-loading of new concepts in the studydesign leads to the generation of new data (Gallagher 2003; Gallagher and Zahavi 2012, 44-45).

To get a better sense of this approach, consider one of Gallagher's examples: In most bodily experiences, the sense of bodily self-agency and the sense of bodily selfownership are nearly indistinguishable. When I walk down the street, drink a cup of coffee, or grab a book off the shelf, I have the tacit sense that I am both the agent of this bodily movement and that it is my body that is moving. However, if someone pushes me, then I do not experience any agency for this movement-I experience the person who pushed me as the agent. Yet I still experience the movement as happening to meI experience my body being pushed. I therefore have an experience of ownership without an experience of agency. As Gallagher stresses, this is not simply a higherorder attribution of agency or ownership. The distinction holds at the level of first-order phenomenal consciousness. As he says, "They are part of a pre-reflective (nonconceptual) self-awareness implicit to the experience of action" (Gallagher 2003, 92). With this conceptual distinction in hand, cognitive scientists can design experimental studies that investigate, for instance, the neurological processes that underpin or correlate with these distinct experiences. Without such a conceptual distinction-and, thus, without the ability to accurately identify the phenomena in question - it would be impossible to design an empirical study that investigates the different mechanisms that underly bodily agency in contrast with bodily ownership.

How can a front-loaded approach be used in qualitative research? Qualitative researchers don't conduct experiments and they aren't concerned with neurobiological mechanisms. But the general principles of front-loading still apply. To put phenomenological concepts to use, qualitative researchers might use the conclusions of their own retrospective interpretations of previous data and analyses to formulate new research questions and an interview protocol. But they may also use critical reinterpretations developed by philosophically trained phenomenologists as a jumping off point for their empirical investigations. Just as Heidegger investigated particular modes of affective situatedness, many philosophically trained phenomenologists investigate particular modes of being in the world. These philosophical investigations are empirical, to a degree, since they draw on and critically engage with empirical research. But they don't typically generate their own data through interviews or analyses. For example, 
one of the most famous applications of philosophical phenomenology is Iris Marion Young's study of feminine body movement (Young 1980). In this study, Young uses Merleau-Ponty's general account of embodiment as a foundation for describing characteristically feminine modes of body comportment. A qualitative researcher interested in women's embodied experiences may, for instance, use Young's philosophical study as a starting point for their own qualitative study, designing interview questions that will help flesh out some of the experiences that Young described in fairly broad strokes. Moreover, this kind of empirical study also has the potential to correct or revise Young's account if the findings conflict with Young's descriptions.

Young's study is just one example of a kind of retrospective phenomenological analysis that can provide conceptual foundations and guiding clues for qualitative researchers. Many philosophically trained phenomenologists provide accounts of, for example, women's experience, African-American experience, the experience of chronic illness, the experience of living with various mental disorders, and so on. Typically, these phenomenological accounts draw upon and critically engage with empirical research. But they don't generate their own data. ${ }^{8}$ There is, therefore, an open question about how broadly their interpretations apply, whether they apply equally to other populations, and so on. These kinds of philosophical studies therefore provide excellent starting points for qualitative researchers to develop their own empirical studies that might flesh out, or even correct, the philosophical accounts.

\section{Designing a phenomenologically grounded study of modal alterations}

Up to this point, our discussion has been fairly abstract. In this section, we provide a concrete example of a PGQR study conducted by one of the authors, focusing primarily on the study-design. This will exemplify how existentials can ground the domain of the study and orient the researcher toward the specific modes that they're concerned with. The study involved in-depth phenomenological interviews with 20 people who had experienced early parental bereavement (between the age of 5-18). The overall aim of the study was to investigate how this kind of profound event in early life may have impacted the overall mode of being in the world of the individual. To achieve such an analysis, the study was phenomenologically grounded by using existentials as lenses for structuring and guiding the interviews. Because the aim was to identify alterations in the overall way of being in the world, the focus of the interview was ex post facto (i.e., backwards-looking at how the loss shaped the experiences of the interview across the life-span). The participants were between 20 and 50 years old and were interviewed for a total of 6-8 hours over the course of 3-4 interviews.

As already discussed in detail above, the kind of phenomenologically grounded study that we propose requires extensive familiarity with and understanding of the relevant existentials. This familiarity allows the researcher to structure and focus his attention on the specific kinds of experiences, or contents of experience, that are relevant to the study. The interview is conducted in an explorative and inherently

\footnotetext{
${ }^{8}$ There are a few exceptions. See, for example, Jenny Slatman's phenomenologically informed qualitative studies of women's experience following a mastectomy (Slatman et al., 2016).
} 
hermeneutic attitude. But this attitude differs significantly from what one might expect from other qualitative studies, such as the semi-structured interviews of IPA, where the exploration is primarily guided by selected themes (Smith et al., 2009), or the completely open attitude of an inductive approach such as grounded theory (Charmaz 2014), where theory is generated exclusively based on methodological gathering and analysis of data. Rather, in a phenomenologically grounded approach, the interview is guided by a phenomenological sensitivity that, to some degree, privileges the researcher's extensive knowledge of existentials. It is important to emphasize that the process of grounding draws exclusively on the structure and dynamics of the existentials. These provide the conceptual framework for the study, allowing the researcher to focus in on the particular modal alterations, which must be investigated empirically; our understanding of the particular mode - in contrast with our understanding of the existentials - emerges from the interview and subsequent data analysis. Hence, by using existentials as a conceptual framework, the researcher does not impose experiential content on the interviewee. Rather, the existential provides a lens that allows the researcher to focus on and explore the specific content that they want to understand and describe with the interviewee.

Grounding the design of the bereavement study had two stages, which parallel our earlier discussion of retrospective and front-loaded phenomenology: (1) The selection of relevant existentials and (2) the articulation of a guiding research question that frames an investigation of the modes of this existential.

\subsection{Selecting the existential and designing a research question}

When designing a phenomenologically grounded qualitative study, the researcher shouldn't simply select an existential at random. Which existentials a researcher should focus on-and how she justifies this focus-will depend on both the phenomenon under investigation and the state of current research on the topic. In the parental bereavement study, the existentials that guided the investigations were selected based on a comprehensive engagement with two sets of literature on grief and bereavement experiences: (1) psychological studies and (2) first-person descriptions from memoirs and poetry that express personal experiences of loss. Critically engaging with these two sets of literature constituted the retrospective stage of the study (analogous to the retrospective use of phenomenology in cognitive science research discussed above). In what follows, we illustrate how these two sets of literature were used to (a) select a relevant existential for the study and (b) design a research question within the domain of this existential. This account should be considered illustrative and not prescriptive. The study investigated modal alterations in a total of five existentials, each of which had separate research questions and interview protocols, and the design process was not identical across these. In fact, the relevance of one existential, namely body memory, was discovered through the interview process itself; nothing in the surveyed literature had highlighted the importance of this aspect of grief (Køster 2020b). In this case, the design stage was not disconnected from the hermeneutics of the interview process.

First, by engaging with the existing psychological (and philosophical) literature on grief, it was clear that grief is recognized as an ambiguous and complex affective phenomenon (O’Connor et al. 2008; Parkes and Prigerson 2013; Boerner et al., 2013). 
According to standard psychological accounts, the emotivity of grief has a wavelike character - what, since Lindemann (1944), has been referred to as 'pangs of grief'.' The affective dimension of grief is therefore predominantly understood as what phenomenologists call an "emotion," that is, a short-lived affective state that is directed toward something within the world - in this case, the lost loved one.

Once this phenomenon-i.e., the affective dimension of grief-was understood within the current scientific literature, memoirs and other first-personal literature on grief were consulted to see if these descriptions enrich or perhaps conflict with the scientific accounts. Roland Barthes' Mourning Diary (2010) provided an especially enlightening perspective. Here, he insists that there is an encompassing affective component integral to his experience of bereavement that is separate from what he calls the 'emotivity' of grief: "Emotion (emotivity) passes, suffering remains" (Barthes 2010, 103), he tells us. Hence, according to Barthes, there is an affective dimension that both precedes and exceeds the emotional level. Barthes consistently refers to this as "suffering" and insists that it is an affective constant, a kind of altered affective tonality that governs the way of being in the world of the individual in much the same way that one's being in the world is modified when in love (Barthes 2010, 126). However, Barthes does not actually describe this affective state in any detail. He points to it as a significant experiential domain and calls it "suffering," yet he provides no systematic description. But this should not be surprising: it was not Barthes' intention with the text. Barthes' diaries point to an affective phenomenon that has not been adequately investigated in the psychological literature and, therefore, motivates the need for a systematic investigation. His first-person accounts suggested a deeper affective alteration - one that doesn't come in waves, but is a pervasive background way of finding oneself affectively attuned to the world. This suggested an alteration in what phenomenologists have traditionally called ground moods (Heidegger [1927] 1962; 2001) and which has more recently been addressed, in a slightly modified form, as existential feelings (Ratcliffe 2008). To avoid terminological confusion, we shall refer to these as existential feelings in the following. This notion is not part of a standard taxonomy in empirical psychology, in which both emotions and moods are defined as temporally delimited states (Coleman 2008). However, as Peter Goldie (2002) has pointed out, this conceptualization characterizes affectivity as purely contingent to experience - an add-on element that temporarily colours and disturbs experiences, implying that the mind is typically free of affect.

Contrary to this, the phenomenologists argue that not only does existence always feel a certain way, but existential feelings are responsible for structuring how we find ourselves in the world. Hence, while emotions express a short-term evaluative attitude towards specific objects, existential feelings are non-intentional or pre-intentional affective states that determine our mode of being in the world. Existential feelings shape our sense of reality and both open and constrain our range of intentional states, including emotions and

\footnotetext{
${ }^{9}$ In DSM-5, grief is also distinguished from Major Depressive Disorder through its wave-like character: "The dysphoria in grief is likely to decrease in intensity over days to weeks and occurs in waves, the so-called pangs of grief. These waves tend to be associated with thoughts or reminders of the deceased. The depressed mood in MDE is more persistent and not tied to specific thoughts or preoccupations" (American Psychiatric Association 2013).
} 
desires. However, while phenomenologists have clearly articulated what existential feelings are, and even provided analyses of particular feelings (e.g., existential anxiety, profound boredom, deep guilt), there has not been a systematic investigation into whether bereavement experiences produce alterations in existential feelings. ${ }^{10}$

It's important to remember that this stage, which critically engages with both the scientific and non-scientific literature, is only the retrospective stage of the analysis. What one can learn from existing literature is necessarily limited. These texts remain a fixed testimony to an experience that can be unpacked only to a limited degree if one does not move beyond the text. Eventually, one exhausts an existing first-person report and will require new data to gain a richer understanding of the relevant phenomenon. This retrospective stage therefore generates new research questions informed by the existing literature. But, to answer these questions, we need to turn to the front-loading stage, in which phenomenological concepts are incorporated into the design of an empirical qualitative study.

The retrospective engagement with the existing literature led to the following guiding research questions: Do profound experiences of bereavement manifest in alterations at the level of existential feelings? If so, how should these changes be characterized from a phenomenological point of view? Importantly, the generation of this research focus was itself created through phenomenological grounding. An explicit and active hermeneutic awareness and sensitivity to phenomenological analysis and conceptuality formed the research focus.

\subsection{The interview-guide and phenomenological sensibility in the hermeneutics of the interview}

The above-mentioned research question formed the basis of one of the project's interview guides, which was specifically aimed at disclosing potential modifications at the level of existential feelings. At this point, it should be noted that the type of interview we are proposing is not one with a pre-defined set of questions that the interviewees should be taken through in a sequence. Rather, the interview guide functions as a broad hermeneutic roadmap for the interview. It steers the interview through a few predefined focus points, which ensure that the research question is explored in a thorough manner. Such focus points included an exploration of a range of overlapping categories that all emphasize how existential feelings are the connective tissue between self and world, such as the character of how it felt to be alive, the feeling of the relation to the world, the embodied sense of presence in the world, and so on. As such, the interview guide is far more theory-loaded and specific in its focus than one would expect from a standard semi-structured and thematically guided approach to interviews (Brinkmann and Kvale 2015). Furthermore, the overlapping nature of the categories was intentional and rooted in the rationale that it is in fact an unfamiliar activity for non-phenomenologists to address this type of phenomenon and that it is therefore productive to reiterate through a variety of phrasings and points of entry.

\footnotetext{
${ }^{10}$ This is not to say that grief has not been a topic of philosophy. In recent years, there has been an increasing interest in grief from a phenomenological perspective (see, e.g., Fuchs 2018; Køster 2019, 2020a, 2021; Ratcliffe 2017, 2020).
} 
Although the structure of the interview guide was already phenomenologically grounded, a more encompassing grounding is found in the inquisitive and hermeneutic attitude of the interviewer. Throughout the interview, the researcher should use his understanding of the existentials to cultivate his attention toward the phenomenon under investigation. The researcher should take up an exploratory attitude, attending to any hints or clues that the interviewee might offer and asking follow-up questions that encourage the interviewee to describe this aspect of their experience in more detail. Certain expressions and statements of the interviewee should be systematically flagged and become the object of dedicated investigations. For example, if an interviewee were asked to describe what he felt like in the period after being bereaved, he might refer to a range of affective states, such as emotions of longing and anger, as well as a general feeling of being distanced from everything. In this case, the interviewer should flag the feeling of being distanced as particularly relevant since it points to what a phenomenologist would recognize as an existential feeling and attempt to systematically unpack it through a series of follow-up questions, such as, "What does it feel like to be distanced?"; "How does one notice distance?"; "How does distance announce itself?"; "Distance from what?"; "Is distance similar to or connected to other feelings?"; etc. Specifically, in respect to existential feelings, which are often expressed in metaphorical and allegoric language (Ratcliffe 2008, 38), it is productive to both invite such types of language and at the same time not assume that these metaphors can be understood off-hand. Rather, metaphors should be extensively unpacked and explored. Quite often, this involves an attitude of lingering with and focusing on the particular phenomenon for a much longer duration than we are used to and comfortable with in everyday conversation. While it might feel familiar to the trained phenomenologist to linger with the process of bringing tacit, pre-reflective experiences to expression, this is a rather unfamiliar activity to an average interviewee and it may feel both tedious and unnecessary. Hence this aspect of the interview should be addressed with the interviewee beforehand.

At this point, the reader might worry that there is something rather circular about this approach, and that the method might run the risk of generating the phenomena it is looking for. Does the strong focus on front-loading not compromise the open explorative attitude that sets qualitative studies apart from more quantitative approaches in psychology? These are valid concerns. However, in response to such worries, we emphasize two key points:

1) Since the focus of PGQR is to explore altered modes of being in the world through modal alterations in existentials, we are dealing with a level of experience that is inherently difficult to access and does not often reveal itself in everyday reflection. This means that the type of descriptions we are looking for will not pop up in the typical and oft-rehearsed self-narratives that may be offered by the interviewees in a qualitative study. Rather, the interviewer needs to push beyond (or below) these scripted narratives in an attempt to evoke descriptions of pre-reflective and often embodied experiences that have not previously been reflected on or narrated by the interviewee. ${ }^{11}$ The interviewee might, for instance, have lived through profound alterations in existential feelings post-bereavement, but without being reflectively

\footnotetext{
${ }^{11}$ For a detailed analysis of this process see (Køster 2017b).
} 
aware of this or able to pin-point and articulate this alteration. Because we investigate experiences that seldom offer themselves in the interviewee's narrative, PGQR relies on front-loading to privilege the researcher's knowledge of existentials.

2) Front-loading the interview does not predetermine the content of the interviewees' descriptions. There is a significant difference between predefining the focus of an investigation and predefining what will emerge from this focus. That is, a predefined focus on existential feelings does not dictate the kind of alteration that might emerge. In fact, it might even turn out that there are no alterations to be found here at all. Therefore, the pre-structured focus developed in the retrospective phase is open to a degree of falsification. Obviously, this should not be taken in a strict sense of hypothesis testing; rather, the assumptions that guide the investigation are sensitive to the concrete experiential content described in the interviews.

\subsection{Examples of descriptions generated}

To illustrate the kinds of descriptions that this type of interview can produce, let's turn to some examples. First, it should be noted that the interviews confirmed the tentative supposition that bereavement manifested in alterations in existential feelings. All the participants, save one, ${ }^{12}$ expressed profound changes in existential feelings in the years immediately following bereavement. Most of them, with significant scalar differentiations in intensity and frequency, considered these changes a lasting disposition and something that characterized their particular mode of being in the world.

The kind of modal alteration reported was similar across all participants and there was a striking similarity in the choice of metaphors used to express this alteration. In a condensed manner, the alteration can be characterized as world-distancing. Briefly stated, world-distancing refers to a continued or recurring feeling of being disconnected from the world. The world appears separate, akin to watching an event from a distance - not standing within the bustling crowd, but observing the crowd while feeling distinctly separate from it, pushed back on yourself and out of the flow of the world. This affective state is a profound existential feeling that has implications on both the experiential dimension of temporality and sociality. The following examples illustrate some aspects of this alteration, but are not exhaustive of it. It should also be noted that these rather clear descriptions provided by informants are the result of a lengthy and laborious collaborative process of bringing experiences to words, which required repetition, lingering, and refining expressions. However, they are exclusively the words of the informants.

Let's start with the following description of a 49-year-old man who lost his mother suddenly at age 12 . He describes the emergence of a world distancing affective attunement in the following way:

\footnotetext{
${ }^{12}$ It is not in itself an aim of PGQR that all the descriptions for the interviewees align or overlap. Contrasts in experiences can provide rich sources for phenomenological elaboration. For an example of how this unpacks see (Køster 2020b, 2021).
} 
To me this feeling of distancing is similar to watching a train running by. It's my life, and I am on the platform watching the train run by. You know, the best metaphor is perhaps looking at a party and, just for a few seconds, having stepped out into the garden and watching the party from afar. You know there are a lot of people, and I have a relation to all of them. Everybody is having fun, but I have stepped outside. I observe it all. And it is perhaps really that observing stance from the outside that best describes the changed feeling. It's a kind of bubbling up. It's a different feeling of being in a blur, like things are a bit out of focus because I experience it from afar. When thinking of this state all I can think of is calmness. There is no noise. Perhaps I can describe it by saying there is no sound. And this kind of displacement was not only an initial feeling. It is a recurring feeling, one that has become a property of my way of being... In this sense the world has become much more twodimensional. It has no depth. The world is no longer as nuanced, I think. There are not as many layers, I think, or that's what I am left with when I say that it's soft and calm. You know, when you observe from a distance, you don't get all the details, some of the senses don't exist, as for instance the sense of smell, because you are watching things from afar.

To anyone familiar with Heidegger's notion of Befindlichkeit or Ratcliffe's expansion of this concept to existential feelings, it should be clear that this description depicts a clear modal alteration in this level of experience. That is, the very mode of being in the world is altered. It is a feeling of "being in a bubble," of "being in a blur," a feeling that alters the way the world manifests in the sense that it is now "more two-dimensional," without color and lacking in sensory qualities, partially because it is observed from afar.

The contours of this description are echoed by a 33-year-old woman who lost her father at the age of 16 . However, she adds an important temporal dimension to this modal change in affective attunement, which illustrates the inherently interrelated constitution of existentials:

I consider it, this feeling of distancing, as almost a metaphysical feeling. I am in my body but the world is cloudy. I am confined to my own shell, and time has stopped; everybody else is continuing their lives, but I am stuck in stillness. It's a kind of vacuum, where time feels abstract. It's a feeling of being fundamentally alone in the world... One might perhaps also say that I feel like I am continuously caught behind a glass plate and watching the world and other people through this screen.

Again, she explicitly refers to the sense of distancing as a feeling, in this case a "metaphysical feeling," that describes a particular way of finding herself in the world. As emphasized, however, she adds a clear temporal dimension to this experience: distancing is a feeling of being "stuck in stillness" because "time has stopped," separated from the temporal flow of the world.

A 28-year-old woman who lost her mother at age 10 complements these descriptions by elaborating on the social implications of world-distancing as a particular mode of attunement: 
I think it is a bit like being in a bubble; well, it's a feeling of being in a bubble and when somebody is talking to you it just becomes this myriad of words, this stream of fuzzy talk, because it is difficult to localize it, because you are caught in your own bubble. One keeps thinking that this is what is happening, and then that only makes it worse. Often, I feel, though, that I am able to tune-in on the conversation, but it is really hard to remain present. I hear the words, but I can't be fully present, so I end up just saying hmmm, and platitudes like "I know that." Sometimes I feel like shaking my head a bit, to see if it disappears, but it's really difficult. It's a bit like having the hiccups and trying to think it away-it does not work. I start thinking that they notice that, they can tell you are not listening. It's really unpleasant. I get this feeling very often, almost daily, since my mum passed. At least it feels like that.

In this passage, she emphasizes how the feeling of distance impacts the capacity to follow the rhythm and resonance of social interaction. She feels cut off from the interaction as a result of the preceding affective state of distance. The broader anatomy of this altered affective integration with the world is complex and it had a profound impact on the overall well-being of the informants. However, the reader might wonder to what extent this state is in fact specific to grief. A similar kind of world distancing is, for instance, sometimes reported in connection to states of dissociation and, from a phenomenologically inspired clinical perspective, Robert Stolorow associates a similar state of world-distancing with trauma more generally (although he specifically uses grief as his example) (Stolorow 2011, 2019). Lastly, world-distancing as an affective state shows similarities to Heidegger's description of anxiety. Our claim is therefore obviously not to propose that world-distancing is exclusive to the experiences of grief. Assuming that an experience is correlated to one specific affective state in this uniform way would be naïve and out of tune with the broader natural history and evolution of our affective repertoire. However, we find it reasonable to expect that there is a certain way that world-distancing manifests or unfolds in grief experiences. Although it far exceeds the scope of this paper to justify and expand on this claim here, we can indicate that there is a particular feeling of existential loneliness associated with postbereavement feelings of world-distancing that differs in kind from other types of trauma (Køster 2019).

These are examples of the descriptions that a PGQR study can generate. Getting to these descriptions is only the first step in the broader research process. Important work is still needed to provide a thorough phenomenological analysis of the kind of experiential modification that they constitute. However, it should also be clear that the kinds of descriptions generated by the focus points and sensitivities of PGQR differ from the descriptions that would flow naturally into a typical grief narrative. Rather, the descriptions emerge as a result of the phenomenological grounding of the interview.

\section{Type of knowledge generated}

As already mentioned, there are a number of well-established phenomenological approaches to qualitative research. So far, we have focused on how PGQR is distinctive by grounding the research process in pre-selected existentials. These existentials 
provide the foundation for well-focused research questions and the design of interview protocols that help the researcher attend to the pre-reflective level of experience. We've also seen the kind of insightful and illuminating descriptions that participants can provide when interviewed through this approach. However, what kind of knowledge do PGQR studies generate? Is PGQR relevant to all types of qualitative research agendas and can it be integrated with all types of qualitative methods? We intend to provide detailed answers to these questions in future work. But, for now, we provide an initial account of the scope and conditions for applications of PGQR.

We are not suggesting that PGQR replace existing phenomenological approaches to qualitative inquiry. Rather, PGQR's conceptual orientation can be integrated with a variety of existing approaches to qualitative research, both phenomenological and nonphenomenological. As we see it, PGQR has its merits in the particular type of knowledge that it generates, which in turn also restricts its range of application. As already mentioned, PGQR investigates altered modes of being in the world. We might also refer to this as the way one finds oneself in the world or the how of one's being in the world. Importantly, these modes or ways are often pre-reflective. One can, in principle, reflect upon one's mode of being. But, in everyday life, how we find ourselves in the world is often tacit or implicit. PGQR orients the researcher toward pre-reflective and embodied aspects of experience and allows the interviewee to articulate these aspects of experience without recourse to ready-made and culturally scripted narratives of experience.

This kind of research broadens our understanding of our pre-reflective experiential life, including how it undergoes alterations in significant life events. However, the kind of knowledge generated by PGQR can also be integrated with other kinds of studies. The prevalence of descriptions of world-distancing as an aspect of the affectivity of grief is, for instance, currently being investigated in an encompassing quantitative study. ${ }^{13}$ Based on this kind of survey material, it will perhaps be possible to determine whether world-distancing differs across types of loss and if it can be predictive of complicated grief reactions or states of prolonged grief disorder.

The specific focus of PGQR also means, however, that PGQR might not be the best choice if one wants to understand, for instance, particular practices, be they cultural or more personal, such as when Ashworth (2016) investigates the practice of gift giving or when van Manen (1990, 104-6) examines childhood secrets. But PGQR may still be able to supplement such studies. For example, while it does not provide resources for understanding the practice of telling or listening to secrets, it may help us understand how holding a secret modifies one's general orientation toward others. PGQR also does not seem obvious for ethnographic research that focuses on social interaction in situ, in so far as these studies aim to understand the logic of human actions within a confined social context or environment, rather than the modes of being that these individuals find themselves in. Moreover, PGQR does not typically inquire into interviewees' opinions, beliefs, or values.

\footnotetext{
13 The prevalence of world distancing as an aspect of grief experiences has recently been investigated as part of a controlled, randomized intervention project titled "TABstudy" based in Aarhus University, Denmark. On the basis of the descriptions generated in PGQR interviews, we developed a psychometric scale of measurement which was sent out to 1600 participants from 2016-2020. The results are currently in the process of being published.
} 
It may also be helpful to show how PGQR differs from a popular approach to applied phenomenology that also draws extensively on the philosophical texts: microphenomenology, which has been developed by Claire Petitmengin and colleagues (Petitmengin 2006; Petitmengin et al., 2019). There are several overlaps between PGQR and micro-phenomenology, such as a focus on bringing pre-reflective experiences to language and the explicit methodological intention of letting the interview be structured and guided by the interviewer's extensive "meta-knowledge" of experiential structures (see, e.g., Petitmengin 2006, 250), which is similar to what we have framed in terms of front-loading. However, at least two constitutive differences should be emphasized.

First, there is a manifest difference in focus: PGQR studies investigate broad existential orientations and characterize alterations in the overall mode of being in the world of the person, partitioned through the lens of existentials. Micro-phenomenology, in contrast, studies particular, temporally delimited cognitive processes, such as specific acts of memorizing or detecting cues for anticipating epileptic seizures (Petitmengin et al., 2006). Such cognitive processes can, according to micro-phenomenology, only be investigated through "singular acts" (Petitmengin 2006, 692). The research protocol for micro-phenomenology provides a rich and detailed methodology for investigating such singular acts. However, it is not obvious how this framework would be appropriate for investigations of broader modes of being in the world. This is not to say that the two frameworks can't supplement each other or that the methodological innovations for investigating singular acts cannot enrich and be applicable to aspects of a PGQR. However, the overall focus is fundamentally different.

Second, micro-phenomenology specifically aims to uncover invariant experiential structures through empirical investigations that move from individual experiences toward "progressively abstract categories" (Petitmengin et al. 2019, 702). PGQR, in contrast, moves in a different direction. It utilizes philosophical accounts of invariant structures, or existentials, to frame empirical investigations of particular modal alterations, which are often generalizable to a population but are not invariant structures of existence. There may be potential for PGQR studies to inform our understanding of invariant structures; but this is not its primary aim.

To which types of inquiry is PGQR therefore suited? It's well-suited for any study where modifications in one's mode of being in the world can reasonably be expected. As noted above, philosophically trained phenomenologists often take modes of being in the world as their primary object of study, even if they don't use this kind of language when characterizing their investigation. A few examples include alterations in modes of affectivity in mental disorders (Ratcliffe 2008; Stanghellini and Rosfort 2013); modes of embodiment in chronic or life-threatening illness, or even following treatment (Aho and Aho 2009; Carel 2013; Nancy and Hanson 2002; Slatman 2016; Toombs 1995); and the discursively shaped modes of both embodiment and spatiality that are characteristic of feminine ways of being (Young 1980). In sum, PGQR generates knowledge by uncovering alterations in the basic modes that constitute how a person finds herself in the world. 


\section{Conclusion}

In this article, we have argued that qualitative research can benefit from a conceptual grounding in philosophical phenomenology. We have proposed PGQR as a framework for this interdisciplinary integration. On this approach, the qualitative researcher frames her empirical study through the concepts and analyses found in philosophical phenomenology. Each stage of a qualitative study, from designing a research question to analyzing the data, should be guided by phenomenological concepts and analyses. This process of phenomenological grounding directs the researcher toward specific existentials, allowing the researcher to investigate the modes of this existential and, thus, one's way of being in the world. This, moreover, enables the researcher to investigate aspects of experience that are typically pre-reflective, orienting the interviewee toward aspects of her experience that she may have been largely unaware of and never before put into words.

Where should we go from here? As we noted above, there's considerably more to say about further stages of research within the PGQR paradigm. We'll need to clarify how phenomenological concepts should inform the interview process, including the dynamics between interviewer and interviewee; how these concepts should be used to analyze interview transcripts; and, also, how the interviews themselves can generate new questions for future studies. This article provides an initial introduction. But we intend to follow up on these aspects of PGQR and develop them in future work.

Acknowledgments We thank Ola Borek, Svend Brinkmann, Shaun Gallagher, Jim Morley, Marta Santillo, Dan Zahavi, and researchers as the "Culture of Grief" for their helpful comments on earlier drafts of this article. This work was supported by the Den Obelske familiefond (\#28153) and the Global Research Network program through the Ministry of Education of the Republic of Korea and the National Research Foundation of Korea (NRF-2017S1A2A2039388).

Open Access This article is licensed under a Creative Commons Attribution 4.0 International License, which permits use, sharing, adaptation, distribution and reproduction in any medium or format, as long as you give appropriate credit to the original author(s) and the source, provide a link to the Creative Commons licence, and indicate if changes were made. The images or other third party material in this article are included in the article's Creative Commons licence, unless indicated otherwise in a credit line to the material. If material is not included in the article's Creative Commons licence and your intended use is not permitted by statutory regulation or exceeds the permitted use, you will need to obtain permission directly from the copyright holder. To view a copy of this licence, visit http://creativecommons.org/licenses/by/4.0/.

\section{References}

Aho, J., \& Aho, K. (2009). Body matters: A phenomenology of sickness, disease, and illness. Lanham: Lexington Books.

American Psychiatric Association. (2013). Diagnostic and statistical manual of mental disorders, 5th edition: DSM-5. Washington, D.C.: American Psychiatric Publishing.

Ashworth, P. (2003). An approach to phenomenological psychology: The contingencies of the Lifeworld. Journal of Phenomenological Psychology, 34(2), 145-156.

Ashworth, P. (2016). The Lifeworld-enriching qualitative evidence. Qualitative Research in Psychology, 13(1), 20-32. 
Barthes, R. (2010). Mourning diary. Hill and Wang.

Boerner, K., Mancini, A.D., and Bonanno, G., (2013). 'On the nature and prevalence of uncomplicated and complicated patterns of grief'. In Complicated Grief: Scientific Foundations for Health Care Professionals, edited by Margaret Stroebe, Henk Schut, and Jan van den bout, 55-67. Routledge.

Braddock, G. (2001). Beyond reflection in naturalized phenomenology. Journal of Consciousness Studies, $8(11), 3-16$.

Brinkmann, S., \& Kvale, S. (2015). Interviews: Learning the craft of qualitative research interviewing. Thousand Oaks: Sage.

Carel, H. (2013). Bodily doubt. Journal of Consciousness Studies, 20(7-8), 178-197.

Charmaz, K. (2014). Constructing grounded theory. Second Edition. Sage.

Colaizzi, P. F. (1978). Psychological research as the phenomenologist views it. In R. S. Valle \& M. King (Eds.), Existential-phenomenological alternatives for psychology (pp. 48-71). New York: Oxford University Press.

Coleman, A. M. (2008). A dictionary of psychology. Oxford: Oxford University Press.

Dahlberg, K., Dahlberg, H., \& Nystrom, M. (2008). Reflective Lifeworld research (Second ed.). Lund: Studentlitteratur.

Dahlberg, K., Todres, L., \& Galvin, K. (2009). Lifeworld-led healthcare is more than patient-led care: An existential view of well-being. Medicine, Health Care and Philosophy, 12(3), 265-271.

Englander, M. (2012). The interview: Data collection in descriptive phenomenological human scientific research. Journal of Phenomenological Psychology, 43(1), 13-35.

Englander, M. (2020). Phenomenological psychological interviewing. The Humanistic Psychologist, 48(1), 54-73. https://doi.org/10.1037/hum0000144.

Fernandez, A. V. (2017). The subject matter of phenomenological research: Existentials, modes and prejudices. Synthese, 194(9), 3543-3562.

Fernandez, A. V. (2018). Beyond the ontological difference: Heidegger, Binswanger, and the future of existential analysis. In K. Aho (Ed.), Existential medicine: Essays on health and illness (pp. 27-42). Lanham, MD: Rowman \& Littlefield International.

Fernandez, A. V., \& Køster, A. (2019). On the subject matter of phenomenological psychopathology. In G. Stanghellini, M. Broome, A. V. Fernandez, P. Fusar-Poli, A. Raballo, \& R. Rosfort (Eds.), The Oxford handbook of phenomenological psychopathology (pp. 191-204). Oxford: Oxford University Press.

Fuchs, T. (2018). Presence in absence. The ambiguous phenomenology of grief. Phenomenology and the Cognitive Sciences, 17(1), 43-63.

Gallagher, S. (2003). Phenomenology and experimental design toward a Phenomenologically enlightened experimental science. Journal of Consciousness Studies, 10(9-10), 85-99.

Gallagher, S. (2012). Taking stock of phenomenology futures. The Southern Journal of Philosophy, 50(2), 304-318.

Gallagher, Shaun, and Denis Francesconi. 2012. 'Teaching phenomenology to qualitative researchers, cognitive scientists, and phenomenologists'. Indo-Pacific Journal of Phenomenology 12 (sup3): 1-10.

Gallagher, Shaun, and Dan Zahavi. 2012. The Phenomenological Mind. Second edition. London; New York: Routledge.

Giorgi, Amedeo. 2009. The descriptive phenomenological method in psychology: A modified Husserlian approach. Duquesne University Press.

Giorgi, A. (2010). Phenomenology and the practice of science. Existential Analysis: Journal of the Society for Existential Analysis, 21(1), 3-22.

Giorgi, A. (2011). IPA and science: A response to Jonathan Smith. Journal of Phenomenological Psychology, 42(2), 195-216.

Goldie, P. (2002). The emotions: A philosophical guide. Oxford: Clarendon Press.

Heidegger, M. (1927) 1962. Being and Time. Translated by John Macquarrie and Edward Robinson. New York, NY: Harper Perennial Modern Classics.

Heidegger, M. 2001. The Fundamental Concepts of Metaphysics: World, Finitude, Solitude. Translated by William McNeill and Nicholas Walker. Bloomington, IN: Indiana University Press.

Heidegger, M. (1987) 2001. Zollikon seminars: Protocols - Conversations-Letters. Edited by Medard Boss. Translated by Franz Mayr and Richard Askay. Evanston, IL: Northwestern University Press.

Høffding, S., \& Martiny, K. (2016). Framing a phenomenological interview: What, why and how. Phenomenology and the Cognitive Sciences, 15(4), 539-564. 
Køster, A. (2017a). Narrative and embodiment - a scalar approach. Phenomenology and the Cognitive Sciences, 16(5), 893-908.

Køster, A. (2017b). Narrative self-appropriation: Embodiment, alienness, and personal responsibility in the context of borderline personality disorder. Theoretical Medicine and Bioethics, 38(6), 465-482.

Køster, A. (2019). Lidelsen i Tabet: Fænomenologiske betragtninger over tabserfaringens affektive dybde. Psyke \& Logos, 40, 38-60.

Køster, A. (2020a). Bereavement and the meaning of profound feelings of emptiness: An existentialphenomenological analysis. In C. Tewes \& G. Stanghellini (Eds.), Time and body: Phenomenological and psychopathological approaches (pp. 125-143). Cambridge: Cambridge University Press.

Køster, A. (2020b). Longing for concreteness: How body memory matters to continuing bonds. Mortality, 25(4), 389-401.

Køster, A. (2021). The felt sense of the other: Contours of a sensorium. Phenomenology and the Cognitive Sciences, 20(1), 57-73.

Langdridge, D. (2007). Phenomenological psychology: Theory, research and method. Harlow: Pearson Education.

Lindemann, E. (1944). Symptomatology and Management of Acute Grief. American Journal of Psychiatry, 101(2), 141-148.

Merleau-Ponty, M. (1945) 2012. Phenomenology of Perception. Translated by Donald Landes. New York, NY: Routledge.

Morley, J. (2019). Phenomenology in nursing studies: New perspectives-commentary. International Journal of Nursing Studies, 93, 163-167.

Nancy, J.-L., \& Hanson, S. (2002). L'intrus. CR: The New Centennial Review, 2(3), 1-14.

O’Connor, M.-F., Wellisch, D. K., Stanton, A. L., Eisenberger, N. I., Irwin, M. R., \& Lieberman, M. D. (2008). Craving love? Enduring grief activates Brain's reward center. Neuroimage, 42(2), 969-972.

Parkes, C.M., and Prigerson, H.G., (2013). Bereavement: Studies of grief in adult life. Routledge.

Petitmengin, C. (2006). Describing One's subjective experience in the second person: An interview method for the science of consciousness. Phenomenology and the Cognitive Sciences, 5(3-4), 229-269.

Petitmengin, C., Baulac, M., \& Navarro, V. (2006). Seizure anticipation: Are Neurophenomenological approaches able to detect Preictal symptoms? Epilepsy and Behavior, 9(2), 298-306.

Petitmengin, C., Remillieux, A., \& Valenzuela-Moguillansky, C. (2019). Discovering the structures of lived experience. Phenomenology and the Cognitive Sciences, 18, 691-730.

Ratcliffe, M. (2008). Feelings of being: Phenomenology, psychiatry and the sense of reality. Oxford: Oxford University Press.

Ratcliffe, M. (2017). Grief and the Unity of emotion. Midwest Studies in Philosophy, 41(1), 154-174.

Ratcliffe, M. (2020). Sensed presence without sensory qualities: A phenomenological study of bereavement hallucinations. Phenomenology and the Cognitive Sciences. https://doi.org/10.1007/s11097-020-09666-2.

Slatman, J. (2016). Is it possible to "incorporate" a scar? Revisiting a basic concept in phenomenology. Human Studies, 39(3), 347-363.

Slatman, J., Halsema, A., \& Meershoek, A. (2016). Responding to scars after breast surgery. Qualitative Health Research, 26(12), 1614-1626.

Smith, J. A. (2010). Interpretative phenomenological analysis: A reply to Amedeo Giorgi. Existential Analysis, 21(2), 186-193.

Smith, J. A. (2018). "Yes it is phenomenological": A reply to max van Manen's critique of interpretative phenomenological analysis. Qualitative Health Research, 28(12), 1955-1958.

Smith, J. A., Flowers, P., \& Larkin, M. (2009). Interpretative phenomenological analysis: Theory. Method and Research: Sage.

Stanghellini, G., \& Rosfort, R. (2013). Borderline depression a desperate vitality. Journal of Consciousness Studies, 20(7-8), 153-177.

Stolorow, R. D. (2011). World, affectivity, trauma: Heidegger and post-Cartesian psychoanalysis. New York: Routledge.

Stolorow, R.D. (2019). 'A phenomenological-contextual, existential, and ethical perspective on emotional trauma'. In The Oxford Handbook of Phenomenological Psychopathology, edited by Giovanni Stanghellini, Matthew Broome, Anthony Vincent Fernandez, Paolo Fusar Poli, Andrea Raballo, and René Rosfort. Oxford: Oxford University Press. https://doi.org/10.1093/oxfordhb/9780198803157.013. 85.

Todres, L., Galvin, K., \& Dahlberg, K. (2007). Lifeworld-led healthcare: Revisiting a Humanising philosophy that integrates emerging trends. Medicine, Health Care and Philosophy, 10(1), 53-63. 
Todres, L., Galvin, K. T., \& Holloway, I. (2009). The humanization of healthcare: A value framework for qualitative research. International Journal of Qualitative Studies on Health and Well-Being, 4(2), 68-77.

Toombs, S. K. (1995). The lived experience of disability. Human Studies, 18(1), 9-23.

van Manen, M. (1990). Researching lived experience: Human science for an action sensitive pedagogy. Ontario: Althouse Press.

van Manen, M. (2016). Phenomenology of practice: Meaning-giving methods in phenomenological research and writing. Routledge.

van Manen, M. (2017). But is it phenomenology? Qualitative Health Research, 27(6), 775-779.

van Manen, M. (2018). Rebuttal rejoinder: Present IPA for what it is-Interpretative psychological analysis. Qualitative Health Research, 28(12), 1959-1968.

van Manen, M. (2019). Rebuttal: Doing phenomenology on the things. Qualitative Health Research, 29(6), 908-925.

Young, I. M. (1980). Throwing like a girl: A phenomenology of feminine body comportment motility and spatiality. Human Studies, 3(1), 137-156.

Zahavi, D. (2019). Forthcoming. 'Applied phenomenology: Why it is safe to ignore the Epoché'. Continental Philosophy Review. https://doi.org/10.1007/s11007-019-09463-y.

Zahavi, D. (2018). Phenomenology: The basics. New York: Routledge.

Zahavi, D. (2020). The practice of phenomenology: The case of max van Manen. Nursing Philosophy, 21(2), e12276. https://doi.org/10.1111/nup.12276.

Zahavi, D., \& Martiny, K. M. M. (2019). Phenomenology in nursing studies: New perspectives. International Journal of Nursing Studies, 93, 155-162.

Publisher's note Springer Nature remains neutral with regard to jurisdictional claims in published maps and institutional affiliations.

\section{Affiliations}

\section{Allan Køster ${ }^{1,2}$ Anthony Vincent Fernandez ${ }^{3,4}$}

1 Department of Communication and Psychology, Aalborg University, 39220 Aalborg, Kroghstræde, Denmark

2 National Danish Center for Grief, Kejsergade 2, 1. og 2. sal, 1155 København K, Denmark

3 University of Oxford, Radcliffe Observatory Quarter 555 Woodstock Road, Oxford OX2 6GG, UK

$4 \quad$ Kent State University, Kent, OH 44240, USA 